\title{
Shock hipovolémico por rotura esplénica no traumática en un paciente adolescente. Una rara manifestación de la mononucleosis infecciosa
}

\author{
Hypovolemic shock due to nontraumatic splenic rupture in adolescent patient. A rare \\ complication of infectious mononucleosis
}

\author{
Jorge Chóliz-Ezquerro*, Marta Allué-Cabañuz y Antonio Martínez-Germán \\ Servicio de Cirugía General, Hospital Universitario Miguel Servet, Zaragoza, España
}

La principal causa de rotura esplénica es el traumatismo abdominal. La rotura esplénica no traumática es una complicación muy infrecuente de la mononucleosis infecciosa $(0,1-0,4 \%)$ y supone una urgencia vital, ya que aumenta la tasa de mortalidad de la enfermedad $(<0,1 \%)$ hasta el $9-13 \%{ }^{1}$.

Presentamos el caso de un varón de 16 años, sin antecedentes, que acude al servicio de urgencias tras presentar un episodio sincopal sin traumatismo asociado. Relata una ligera epigastralgia referida al tórax, náuseas y vómitos. A su llegada, presentaba hipotensión (97/46 mmHg) y taquicardia (112 I.p.m.). La exploración evidenció abdomen doloroso con signo de Kehr positivo. El hemograma demostró anemia grave (hemoglobina $6 \mathrm{~g} / \mathrm{dl}$ ) y 31.000 leucocitos $/ \mathrm{ml}$. Se realizó una ecografía FAST (Focused Abdominal Sonography for Trauma) que no fue concluyente, por lo que tras estabilizar al paciente se le realizó una tomografía computarizada abdomino-pélvica urgente que informó esplenomegalia con hematoma subcapsular esplénico, con puntos de sangrado activo en el polo posteroinferior, compatible con rotura esplénica (Fig. 1). El mono-test resultó positivo, así como la confirmación posterior con anticuerpos VCA-IgM. Tras la resucitación inicial mediante fluidoterapia intensiva y transfusión de dos bolsas de concentrados de hematíes y ácido tranexámico, se trasladó al paciente al quirófano de urgencia. Se accedió mediante laparotomía media y se evidenció hemoperitoneo masivo de $3000 \mathrm{ml}$ e importante esplenomegalia con rotura del polo inferior que presentaba sangrado activo, por lo que se realizó esplenectomía. El paciente evolucionó de forma favorable y fue dado de alta a los 5 días.

La mononucleosis infecciosa afecta principalmente a niños y adolescentes, y en general cursa como un cuadro viral inespecífico. La esplenomegalia aparece en la mitad de casos y, al acumularse células linfoides en el parénquima esplénico, este es más frágil y aumenta el riesgo de rotura ${ }^{2}$.

Hay que pensar en esta patología ante pacientes jóvenes que acuden a urgencias con un cuadro viral inespecífico, dolor abdominal e inestabilidad hemodinámica. El signo de Kehr (dolor irradiado al tórax y el hombro izquierdo al comprimir el hipocondrio izquierdo) o el de Danforth (dolor irradiado al hombro izquierdo con la inspiración) apoyan esta sospecha, pero debe confirmarse mediante pruebas de imagen (ecografía FAST en el paciente inestable o tomografía computarizada en caso de estabilidad hemodinámica) $)^{3}$.

Tradicionalmente, la esplenectomía ha sido el tratamiento de elección para la rotura esplénica, pero cada vez más se prefiere el tratamiento no quirúrgico en pacientes hemodinámicamente estables ${ }^{4}$ con el apoyo de radiología intervencionista y tratamientos

\footnotetext{
Correspondencia:

*Jorge Chóliz-Ezquerro

La Paz 13, 1ํ Izquierda

C.P. 50008 Zaragoza, España

Fecha de recepción: 06-04-2020

Fecha de aceptación: 26-04-2020

Cir Cir. 2021;89(6):844-845

E-mail: jorgecholiz@gmail.com

DOI: 10.24875/CIRU.20000279

Contents available at PubMed

www.cirugiaycirujanos.com

0009-7411/@ 2020 Academia Mexicana de Cirugía. Publicado por Permanyer. Este es un artículo open access bajo la licencia CC BY-NC-ND (http://creativecommons.org/licenses/by-nc-nd/4.0/).
} 


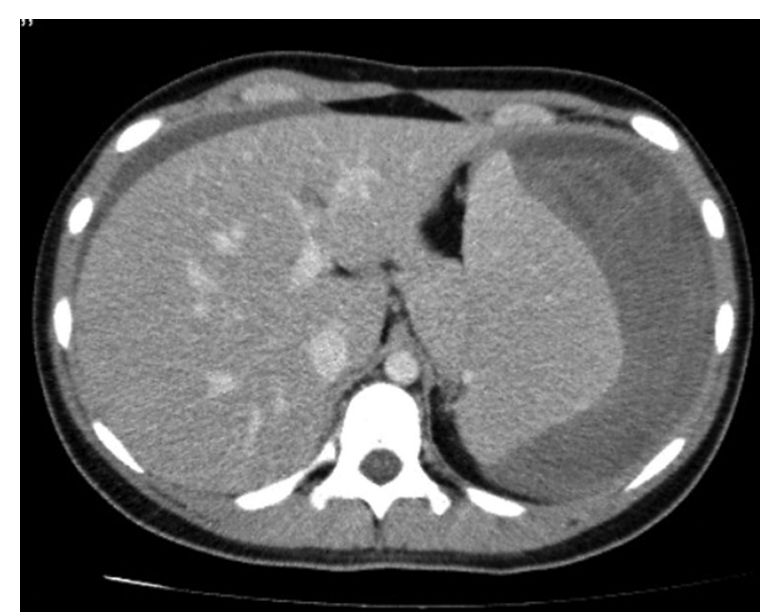

Figura 1. Tomografía computarizada que muestra esplenomegalia de $17,5 \mathrm{~cm}$ en el eje mayor, hematoma subcapsular multilaminar $y$ hemoperitoneo.

endovasculares, sobre todo en población infantil y adolescente, en la que el riesgo de sepsis postesplenectomía es mayor ${ }^{5}$.

Son fundamentales la sospecha clínica (incluso en ausencia de traumatismo abdominal), la rápida instauración de medidas de resucitación inicial y la coordinación desde el servicio de urgencias con cirugía para evitar la alta mortalidad de esta afección.

\section{Agradecimientos}

Los autores agradecen al Servicio de Cirugía General y Digestivo, y al Servicio de Urgencias, del Hospital Universitario Miguel Servet.

\section{Financiamiento}

Los autores declaran no tener ninguna fuente de financiamiento.

\section{Conflicto de intereses}

Los autores declaran no tener ningún conflicto de intereses.

\section{Responsabilidades éticas}

Protección de personas y animales. Los autores declaran que para esta investigación no se han realizado experimentos en seres humanos ni en animales.

Confidencialidad de los datos. Los autores declaran que han seguido los protocolos de su centro de trabajo sobre la publicación de datos de pacientes.

Derecho a la privacidad y consentimiento informado. Los autores han obtenido el consentimiento informado de los pacientes y/o sujetos referidos en el artículo. Este documento obra en poder del autor de correspondencia.

\section{Bibliografía}

1 Bartlett A, Williams R, Hilton M. Splenic rupture in infectious mononucleosis: a systematic review of published case reports. Injury. 2016;47:531-8.

2. Gilmartin S, Hatton S, Ryan J. Teenage kicks: splenic rupture secondary following infectious mononucleosis. BMJ Case Rep. 2019;12:2018-9.

3. Torino JR, Fernández J, Pitti S, Sabatel R, Manzano C. Rotura espontánea en bazo normal. A propósito de un caso. Emergencias. 2001;13:390-1.

4. Fodor M, Primavesi F, Morell-Hofert D, Kranebitter V Palaver A Braunwarth $E$, et al. Non-operative management of blunt hepatic and splenic injury: a time-trend and outcome analysis over a period of 17 years. World J Emerg Surg. 2019:14:1-12.

5. Madenci AL, Armstrong LB, Kwon NK, Jiang W, Wolf LL, Koehlmoos TP, et al. Incidence and risk factors for sepsis after childhood splenectomy. J Pediatr Surg. 2019;54:1445-8. 